Out of the 12 patients reported, 4 failed to achieve full dilatation by their method and the application of the suction cup to a high head would certainly in my opinion carry some risk which I think has been demionstrated very clearly when the instrument was applied to a deflexed unengaged head which extended to a brow presentation subsequently, and cæsarean section had to be performed. I would therefore disagree with the conclusion that " there were no hazards associated with this method". Moreover, I think this series is too small to determine whether any dislodgement of the placenta could or could not be caused by this approach.

Finally, the concept of " early fotal distress " is not generally known in this continent, but most of us believe that when there is a cardiac irregularity of the fotus a careful pelvic examination and artificial rupture of the membrane is indicated, because the presence or absence of meconium-stained amniotic fluid would be a very useful guide to diagnosis. I hope that Dr. Jones and his colleagues will have a control series for us in the not too distant future.

Windsor, Ontario.

ANDREW A. FreIER.

\section{COMMONWEALTH SCHOOLS}

SIR,-Dr. Whitfield and Dr. McCall (June 15) stated that it would not be possible to impose the E.C.F.M.G. examination on overseas graduates coming to work in British hospitals because the vast majority of them are already British subjects (I presume they meant Commonwealth citizens). A hospital is in no way obliged to accept a doctor on its staff because he happens to be a British subject, and so I cannot see that the nationality of these overseas doctors has any bearing on their suitability for employment in British hospitals, or that it makes it impossible to impose the E.C.F.M.G. examination on them.

It seems, from their article, that the British hospital service might find some use for an examination similar to that of the E.C.F.M.G. If so, why not use the one already in existence? The examination can be taken in 82 centres outside the U.S.A.; 8181 doctors sat the examination abroad in October, 1962, and $68 \%$ of them received either the standard or temporary certificate. ${ }^{1}$ Surely, it would be better if the overseas graduates had professional screening of this type done in their homeland before they set out for Britain.

University of Michigan Medical Center, Ann Arbor, Michigan.

Bernard NAYLOR.

\section{HALOTHANE}

SIR,-I must rise to the " simple" explanation that the alleged hepatoxicity of halothane is connected with the low flow-rates employed with the semi-closed system in the United States of America, as suggested by Dr. Seigleman (June 22).

It would be more in line with his reasoning to have postulated that those using halothane in a closed system were guilty of causing some carbon-dioxide retention. This would be particularly evident when employing the Marret technique ${ }^{2}$ with the vaporiser inside the circle system (a method more commonly seen in the United Kingdom) when spontaneous respiration is advocated.

In fact, halothane hepatoxicity is neither a " simple" nor a geographical issue, and at the present time an ad-hoc committee of the National Research Council, under the chairmanship of Dr. John Bunker, is looking into the matter. Until their findings are made known those who retain an unqualified confidence in halothane will con- tinue to use it without reservation. Others who have always distrusted the " smelly" stuff will doubtless return to the techniques of Gray and Halton ${ }^{3}$ or other suitable alternatives available to the modern anæsthetist.

Cleveland Metropolitan
General Hospital,

General Hospital,
Cleveland, 9, Ohio.

JoHN HOMI.

\section{CLINICAL RESEARCH}

SIR,-Your survey ${ }^{4}$ of this subject recites the criticism of the present conditions, but I feel that its recommendations should have been stronger. Setting up another committee, on which all the big grant-giving bodies are represented, is not, in my opinion, going to do much good, and I should like to make some other suggestions.

In the first place, nearly all projects have small beginnings, and most of the young workers whom you refer to as likely to engage in clinical research, part-time or for short periods, will require relatively small amounts of money, and these are far too difficult to obtain. If a trust or committee is accustomed to deal in tens of thousands of pounds it is not going to bother to inquire into a proposal to spend $£ 250$ or $£ 1000$. Experience has shown (and you give an example) that when small sums are made available there is a big demand for them. Every big fund might well have a "petty-cash" section, and it should be in charge of someone who is prepared and interested to deal in hundreds.

Secondly, having spent (wasted!) a lot of my own time and failed to obtain $£ 250$ after sounding six research organisations, starting with the Ministry and the regional board, I realised that what I required was an agent. What I required was a " contact-man "- -someone who would know all the sources of funds, big and small, and the peculiarities and preferences of each. There are now a great many funds of different kinds, and such a person would soon get to know which ones might be interested in a particular proposal, and would, I believe, be more effectual than the committee you suggest.

How such an agency could best be provided is a matter for discussion. My own view is that it should be separate from the big battalions-from the Ministry and the M.R.C., but not necessarily from the universities. The Royal Colleges, jointly, might establish such an office.

The agent would conduct the preliminary inquiries, the tentative nature of which you rightly stress, and then bring the parties together. It is obvious that he could be of great help to deans of medical schools and institutes and to heads of departments as well as private individuals.

Once such an agency was established it would probably be able to tap new sources of funds. I have never understood why the life assurance companies in this country did not endow medical research, when it is obviously so much in their interest to do so, and when they have practical experience of the great benefits to be derived from it. Now that the oil companies and the engineering companies have shown the way in endowing basic research in their own departments, perhaps the life assurance group would be more ready to follow if the way was made easy for it. Apart from this, there is a place for private patronage, and both individual benefactors and business firms might be "touched" on occasion.

I will comment on only one other point. You seem to imply that every region has a research committee. If so, its secretary should not be the medical adviser to the 